\title{
The changing landscape of pulmonary arterial hypertension and implications for patient care
}

\author{
Marius M. Hoeper ${ }^{1}$ and J. Simon R. Gibbs ${ }^{2}$
}

Affiliations: 'Dept of Respiratory Medicine, Hannover Medical School and German Centre of Lung Research (DZL), Hannover, Germany. ${ }^{2}$ National Heart and Lung Institute, Imperial College London, London, UK.

Correspondence: Marius M. Hoeper, Dept of Respiratory Medicine, Hannover Medical School, Carl-NeubergStr 1, Hannover 30627, Germany. E-mail: hoeper.mariusđamh-hannover.de

ABSTRACT Registries have provided a wealth of information on the clinical and disease characteristics of patients living with pulmonary arterial hypertension (PAH) since the 1980s. Certain PAH demographics, such as the prevalence of various PAH subgroups and preponderance of female patients, appear to have remained stable over time. Contemporary registry data indicate that the average age of patients diagnosed with PAH has increased, at least in the Western world. Older patients with PAH are more likely to be diagnosed with a more advanced stage of the disease, have lower exercise capacity and present with multiple comorbidities. They also have worse survival compared with younger patients. Within the PAH population, there is also a subset of patients with a lower diffusing capacity of the lung for carbon monoxide who are generally older and display more severe disease characteristics. This review discusses the implications that the increased age of the PAH population at diagnosis has on the treatment and management of the disease, as well as the need for earlier and improved diagnosis in these patients.

@ERSpublications

PAH demographics: what has changed? The implications for patient care http://ow.ly/C6RT6

\section{Introduction}

Pulmonary arterial hypertension $(\mathrm{PAH})$ is a progressive disease characterised by elevated pulmonary arterial pressure (PAP) and pulmonary vascular resistance (PVR), leading to right ventricular failure and death [1]. $\mathrm{PAH}$ is a rare disease, with an estimated prevalence ranging from 10 to 52 cases per million [2-7].

PAH (Group 1 pulmonary hypertension $(\mathrm{PH})$ ) is subcategorised according to the underlying disease pathogenesis [8]. This includes idiopathic (I)PAH, heritable (H)PAH caused by gene mutations, drug- and toxin-induced PAH and PAH associated with conditions such as connective tissue disease (CTD)-PAH, HIV-PAH, congenital heart disease (CHD)-PAH and schistosomiasis. The correct diagnosis of patients is important, as the prognosis and management for each subcategory is different. For example, the prognosis is generally worse in patients with CTD-PAH, while patients with CHD-PAH usually have a better prognosis compared with patients in other subgroups [5, 9-12].

Over the past 30 years a number of PAH registries have collected data on the demographic, clinical and haemodynamic characteristics of patients with PAH [4-7, 10, 11, 13-17]. They have provided a wealth of information on the epidemiology and survival rates of patients with $\mathrm{PAH}$, and have facilitated the development of prognostic indicators for the disease [18]. Several prognostic equations have been developed on the basis of registry data that can be used to determine the probability of survival over time $[11,12,19,20]$.

Received: Sept 012014 | Accepted after revision: Sept 252014

Conflict of interest: Disclosures can be found alongside the online version of this article at err.ersjournals.com

Provenance: Publication of this peer-reviewed article was sponsored by Actelion Pharmaceuticals Ltd, Allschwil, Switzerland (principal sponsor, European Respiratory Review issue 134).

Copyright OERS 2014. ERR articles are open access and distributed under the terms of the Creative Commons Attribution Non-Commercial Licence 4.0. 
Recent data from various PAH registries indicate that the demographics of IPAH patients have changed. In the US National Institutes of Health (NIH) registry in the 1980s PAH was typically diagnosed in young adults [17], but more recent registry data depict a shift towards diagnosing PAH in older patients [3, 6, 9, 13, 21-23]. This may have implications for the diagnosis, treatment and management of patients with PAH.

Here, we review the changes in demographics of patients with $\mathrm{PAH}$ over the past decades, explore the possible reasons for the observed increase in the age of patients diagnosed with $\mathrm{PAH}$, and the potential clinical implications for patient's treatment and management resulting from this change.

\section{Changing demographics in PAH patients \\ PAH aetiology}

The most commonly reported subtype of PAH in adult patients is IPAH, followed by PAH associated with concomitant diseases such as CTD, CHD or portal hypertension (so-called portopulmonary hypertension) $[4,7,9,12]$. Depending on the registry, the proportions range from $39 \%$ to $61 \%$ for IPAH, $11-28 \%$ for CTD-PAH, 10-20\% for CHD-PAH and 5-10\% for portopulmonary hypertension-PAH [4, 7, 9, 12]. These findings do not appear to have changed over time. For example, approximately the same relative proportions of the various aetiologies were reported in the US REVEAL (Registry to Evaluate Early and Long-term PAH Disease Management) registry in 2006-2009 $[9,12]$ as were reported in the earlier US Pulmonary Hypertension Connection registry, which collected data retrospectively and prospectively from 1982 to 2006 [11, 24]. During this time, the proportion of patients with IPAH/familial PAH decreased, while the proportion with CTD-PAH increased [24].

\section{Proportion of male and female patients}

In general, registry data indicate a greater incidence of PAH in female patients; on average registries report $70-80 \%$ female PAH patients [18]. In the US registries, the proportion of female to male patients appears to have increased over time [3]. Female patients accounted for $63 \%$ of IPAH patients in the NIH registry undertaken in the 1980s [17], whereas this had increased to $80 \%$ in the more recent REVEAL registry [15]. The female/male ratio is influenced by several factors including geography, age and aetiology. In addition, REVEAL mostly included prevalent patients and the female predominance may have been, to some extent, related to the fact that male patients tend to die earlier from PAH [25]. The REVEAL registry reports more female IPAH patients compared with the French registry: 80\% [15] versus 62\% [4]. Although similar geographical differences in the female/male ratio have been observed within the IPAH population [18], it is unclear why these differences occur. Variation in the female/male ratio with age has been indicated in data from the COMPERA (Comparative, Prospective Registry of Newly Initiated Therapies for Pulmonary Hypertension) registry. This registry reports that in younger patients (median age 54 years) the female/male ratio was 2.3/1, while in older patients (median age 75 years) this ratio was almost even, at 1.2/1 [13]. Data from the REVEAL registry indicate that the proportion of female patients varies according to the underlying aetiology of the PAH subgroup to which they belong. For example, in patients with IPAH, $80 \%$ were female compared with $50 \%$ in patients with portopulmonary hypertension-PAH and $90 \%$ in the CTD-PAH subgroup [15].

\section{Age at diagnosis}

IPAH is increasingly diagnosed in older patients (table 1). While the NIH registry reported a mean \pm SD age at diagnosis of $36 \pm 15$ years in IPAH patients [17], contemporary registries report older populations ranging from $50 \pm 17$ years to $65 \pm 15$ years $[3-7,9,11-15,19,23,27]$. A recent audit of $\mathrm{PH}$ patients in the UK from 2013 reported that $21 \%$ of PAH patients were in the 60-69 years age bracket [27], similar to previous audits in 2010-2012 [28-30]. Data from the PH registry of the UK and Ireland in 2001-2009 reported that $26 \%$ of patients were aged $51-65$ years and $23 \%$ were aged $>65$ years [6].

The change in age profile that has been observed between older and more contemporary registries has also been observed within registries. The PH registry of the UK and Ireland found a significant increase in the age of patients over the period from 2001 to 2009 [6]. Similarly, data from the Czech registry in 2000-2007 showed that patients diagnosed during 2007 were 10 years older than the population diagnosed prior to 2007 [7].

Whilst registries provide an invaluable source of information regarding disease epidemiology and outcome, the data they contain is influenced by external factors which could explain some of the discrepancies observed between registries. For example, data from the NIH PAH registry may not be as relevant to patients today due to the changes in PAH classification and novel treatment options that have arisen in the intervening years [31]. A number of additional independent factors that have been suggested to influence registry data include: 1) access to $\mathrm{PAH}$ therapies; 2) referral patterns; 3) the increased interest in $\mathrm{PH}$ from physicians and, thus, an increase in the available information about the disease; 4) increased disease awareness; 5) increased patient access to information; and 6) widespread use of noninvasive screening tools [18]. 
TABLE 1 Demographics of idiopathic pulmonary arterial hypertension patients over time

\begin{tabular}{|c|c|c|c|c|c|}
\hline Registry & [Ref.] & Time period & Age years & Female & 1-year survival \\
\hline French registry & {$[4,19,23]$} & $2002-2003$ & $52 \pm 15$ & 62 & 89 \\
\hline PH registry of the UK and Ireland ${ }^{\#, 9}$ & [6] & $2001-2009$ & $50 \pm 17$ & 70 & 93 \\
\hline COMPERA $^{+}$ & [13] & $2007-2011$ & $65 \pm 15$ & 60 & 92 \\
\hline New Chinese registry & [26] & $2008-2011$ & $38+13$ & 70 & 92 \\
\hline
\end{tabular}

Data are presented as mean \pm SD or \%, unless otherwise stated. NIH: National Institutes of Health; REVEAL: Registry to Evaluate Early and Longterm PAH Disease Management; PH: pulmonary hypertension; COMPERA: Comparative, Prospective Registry of Newly Initiated Therapies for Pulmonary Hypertension. " : included idiopathic pulmonary arterial hypertension (PAH), familial/heritable PAH and anorexigen-associated PAH; ๑: incident population; ${ }^{+}$: countries involved included Austria, Belgium, Germany, Italy, the Netherlands, Switzerland and the UK.

Awareness among physicians of the prevalence of PAH in older patients is increasing. In the past, PAH was viewed as a disease of younger females and the diagnosis was often not considered in older patients and males; this may have contributed to males being underdiagnosed and, therefore, underrepresented in earlier registries [18]. There have also been improvements in the clinical diagnosis of PAH. It is possible that, in the past, older patients could have been misdiagnosed with other pathologies such as left heart disease and, thus, misclassified into other types of $\mathrm{PH}[13,18]$. Also, some of the PAH diagnoses in the elderly could be misclassification of $\mathrm{PH}$ in association with left heart disease. In recent years, diagnostic algorithms have been updated [32, 33] that aid physicians in the diagnosis of PAH. Additionally, screening programmes [7] have increased the number of PAH referrals and increased use of diagnostic techniques, such as Doppler echocardiography, may influence rates of diagnosis [18].

In contrast to some other registries, the Chinese registry of IPAH patients reported a mean age at diagnosis of 36 years in 1999-2004 and 38 years in 2008-2011 [16, 26]. The reasons for the differences between countries may lie in differences between healthcare systems and in population age distribution [34]. Thus, the question remains whether the PAH population itself is changing, or if independent factors such as those discussed above are influencing certain changes that have been observed in the demographics of PAH patients. Although certain patient characteristics remain unchanged over time, most registry data indicate that the average age of patients identified with $\mathrm{PAH}$ is increasing. This has several implications for the management of PAH in elderly patients.

\section{Clinical characteristics and survival in elderly patients with PAH}

Older patients with PAH are diagnosed with more advanced, severe disease. While younger patients with $\mathrm{PAH}$ are more likely to be diagnosed in New York Heart Association (NYHA)/World Health Organization (WHO) functional class I/II, older patients generally have a more severe functional class (III/IV) $[6,13]$. The COMPERA registry reported that $5 \%$ of patients aged $>65$ years were in NYHA functional class II at baseline versus $17 \%$ of patients aged $18-65$ years, $77 \%$ versus $72 \%$ were in functional class III, and $18 \%$ versus $11 \%$ were in functional class IV, respectively [13]. In addition, older patients have reduced exercise capacity, displaying lower 6-min walking distance (6MWD) values $[6,13]$.

The PH registry of the UK and Ireland reported that the median duration of symptoms at the time of diagnosis was 24 months in patients aged >50 years, compared with 12 months for patients aged $\leqslant 50$ years $(\mathrm{n}=404, \mathrm{p}<0.001)$ [6]. This may be linked to the fact that older patients have more comorbidities than younger patients [6]. Increased incidence of ischaemic heart disease (24\% versus $1 \%$, $\mathrm{p}<0.001$ ), hypertension ( $42 \%$ versus $11 \%, \mathrm{p}<0.001$ ), atrial fibrillation ( $11 \%$ versus $0 \%, \mathrm{p}<0.001$ ), diabetes $(23 \%$ versus $5 \%, \mathrm{p}<0.001)$ and hypothyroidism $(16 \%$ versus $8 \%, \mathrm{p}=0.005)$ have been reported in older patients ( $>50$ years) when compared with younger patients ( $\leqslant 50$ years) [6]. The presence of multiple comorbidities may mask the symptoms of PAH and could account for late diagnosis of PAH in elderly patients and poorer survival.

While contemporary registries indicate that the survival rates of $\mathrm{PAH}$ patients have generally improved over the years [18], age-related survival differences exist (fig. 1) [13]. The COMPERA registry found that 1-, 2and 3-year survival rates were significantly lower in patients aged $>65$ years $(\mathrm{p}<0.001)$, even when adjusted for age and sex [13]. All-cause mortality in the overall COMPERA population was $18 \%$. The cause of death was reported as PH or right heart failure in $66 \%$ of patients [13], but it is unknown whether the causes of death 
differed between the younger and older patients. Factors associated with increased risk of death in elderly patients included male sex, lower 6MWD, higher mean PAP, higher PVR and lower mixed-venous oxygen saturation [13]. After multivariate analysis, only male sex and lower 6MWD remained significant. Similarly, the PH registry of the UK and Ireland found that patients aged $>50$ years with IPAH, HPAH or anorexigenassociated PAH had three times the risk of death compared to younger patients $(p<0.001)[6]$. The worse survival associated with advanced functional class $[5,10-12,16,23]$ and worse 6 MWD $[35,36]$, together with a longer duration of symptoms before diagnosis [6] and advanced age, probably contribute to this.

Haemodynamic impairment (mean PAP and PVR) appears to be less severe in older patients [6, 13]. A possible explanation is that younger patients tend to have a right ventricle capable of preserving cardiac output at higher PVR than older patients; the ability of the right ventricle to generate high pressure falls with increasing age, resulting in older patients becoming symptomatic at lower PVR levels [13]. Despite this less severe haemodynamic impairment, older patients have a lower physiological reserve to cope with this disease than younger patients [6].

\section{Implications for management and treatment of PAH in elderly patients}

Patient management may also be influenced by an ageing PAH population. The interpretation of the treatment goals, such as exercise capacity, may need to be individualised based on the age of the patient and take into account any comorbidities present. In addition, achieving functional class I or II may not be realistic in elderly patients.

It is unclear whether the increasing age of PAH patients has implications for treatment strategies. An observational study from the $\mathrm{PH}$ registry of the UK and Ireland reported that patients aged $>50$ years were less likely to have received more than one $\mathrm{PAH}$ therapy ( $35 \%$ versus $57 \%$; $<<0.001$ ), triple combination therapy ( $1 \%$ versus $11 \% ; \mathrm{p}<0.001)$, prostacyclin analogues $(28 \%$ versus $52 \% ; \mathrm{p}<0.001)$ or calcium channel blockers $(3 \%$ versus $10 \% ; \mathrm{p}=0.002$ ) compared with younger patients ( $\leqslant 50$ years) [6], indicating that older patients may be treated less aggressively despite their more advanced disease. Similarly, data from the COMPERA registry showed that, in the first 3 months of treatment, fewer older patients (aged $>65$ years) received prostacyclin analogues $(6 \%$ versus $14 \%, \mathrm{p}=0.003)$, endothelin receptor antagonists $(63 \%$ versus $71 \%, \mathrm{p}=0.056)$ and combination therapy $(13 \%$ versus $19 \%, \mathrm{p}=0.07)$ compared with younger patients (aged $\leqslant 65$ years) [13]. Older patients also had a higher rate of endothelin receptor antagonist treatment discontinuation. After 12 months of treatment the older patients displayed less improvement in 6MWD with a median increase of $30 \mathrm{~m}$ compared with $50 \mathrm{~m}$ in younger patients $(\mathrm{p}=0.028)$ [13].

\section{Subset of patients with low diffusing capacity of the lung for carbon monoxide}

A low diffusing capacity of the lung for carbon monoxide (DLCO) is usually observed in patients with pulmonary veno-occlusive disease, $\mathrm{PH}$ patients with emphysema and interstitial lung disease, or patients with systemic sclerosis-associated PAH, all of whom have a worse prognosis compared with IPAH patients [9, 37-39]. Patients with PAH usually tend to have a lower DLCO compared with age- and sex-matched
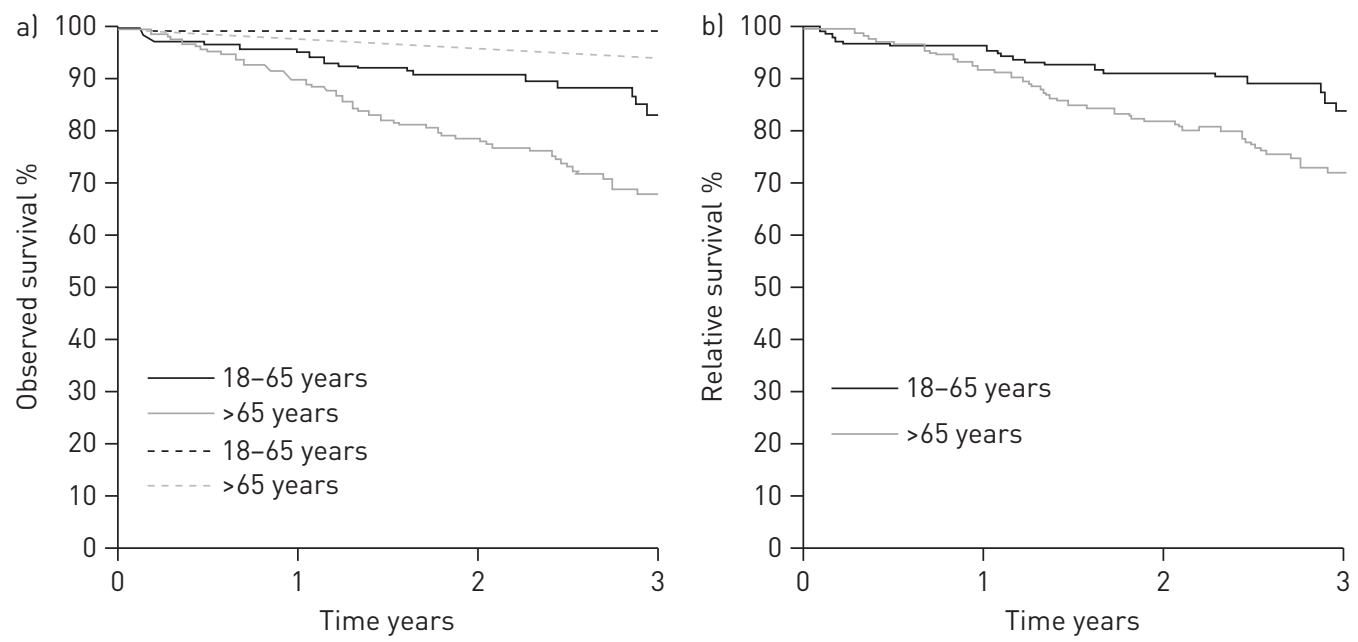

FIGURE 1 Survival rates in older (>65 years) compared with younger (18-65 years) patients with idiopathic pulmonary arterial hypertension. a) Expected (- - - ) and observed (_-) survival rates and b) age-/sex-matched survival rates. Reproduced from [13] with permission from the publisher. 


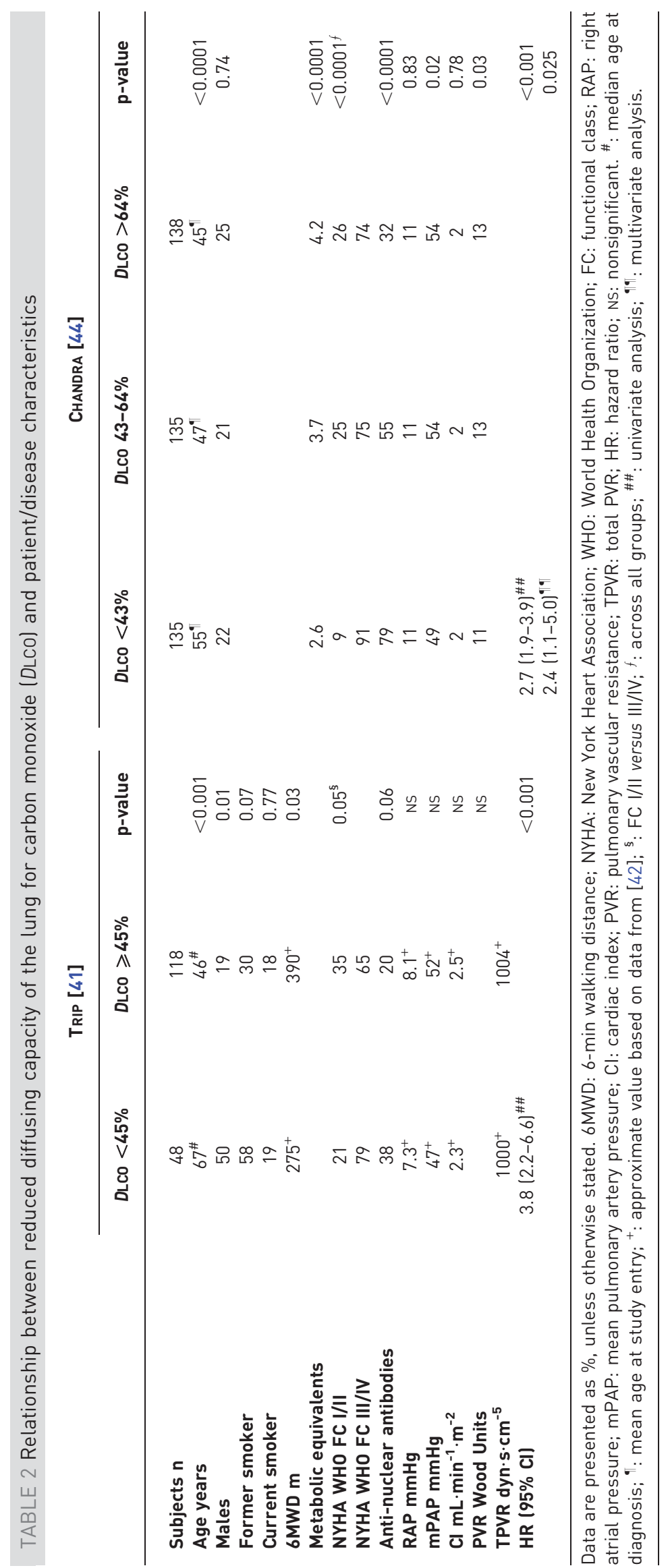


controls $(66 \%$ versus $85 \%, \mathrm{p}<0.001$ ), and DLCO has been shown to be lower in CTD-PAH compared with CHD-PAH (56\% versus $71 \%$, $\mathrm{p}<0.01)[40]$.

In addition to these well-defined patient populations, there seems to be a subgroup of PAH patients presenting with a DLCO arbitrarily defined as $<45 \%$ predicted who have significantly poorer survival compared with patients with a DLCO $\geqslant 45 \%$ predicted [41]. These patients are usually older than the general PAH population, more likely to have a history of smoking and have a significantly higher mortality [41]. Some of these features may be linked to the fact that the patients with a low DLCo tend to be older but some of the abovementioned clinical features suggest that these patients may also have a different type of pulmonary vasculopathy [42].

Data from PAH registries have indicated that having a low DLCO is associated with an increased risk of death in both univariate and multivariate analyses; hazard ratios from 1.5-4.2 have been reported $[12,22,41,43-45]$. In addition, two large cohort studies have found that having a lower than predicted DLCO is linked to more advanced WHO functional class, older age and reduced exercise capacity (table 2). TRIP et al. [41] found no differences in incidence of conditions that may influence DLCO, such as mild chronic obstructive pulmonary disease or asthma, between groups. Reanalysis of computed tomography (CT) scans (140 out of 166 patients) identified more abnormalities in patients with a DLCO $<45 \%$ compared with patients having a DLCO $\geqslant 45 \%$; this may be linked to the increased history of smoking observed in these patients. Approximately half of the patients (57\%) with DLCO $<45 \%$ and abnormalities on CT displayed signs of mild or moderate emphysema without fibrosis. In addition to having a lower than predicted DLCO, patients had a significantly lower total lung capacity, forced expiratory volume in $1 \mathrm{~s}$ (FEV1) and FEV1/forced vital capacity (FVC) ratio. CHANDRA et al. [44] found no evidence of interstitial lung disease in their cohort. There was a greater incidence of lung parenchymal abnormalities on chest CT and significant reductions in total lung capacity, FEV1 and FVC were observed, with no difference in the FEV1/FVC ratio in patients with a reduced DLCO [44].

This additional subset of PAH patients appears to have more severe disease characteristics. They may be difficult to diagnose and would therefore benefit from greater awareness, and possibly from inclusion as a $\mathrm{PH} / \mathrm{PAH}$ subset in future guidelines.

\section{Conclusion}

Comparing data from early PAH registries with those comprising a more contemporary patient population has indicated a shift towards an older age of diagnosis for patients with PAH. Although both disease awareness and diagnosis have changed, challenges still exist for the diagnosis of PAH in older patients, with elderly $\mathrm{PAH}$ patients still experiencing a longer duration of symptoms before receiving a diagnosis compared with younger patients. Within the population of older patients with PAH it is important to distinguish patient subgroups to better tailor treatment, yet it is still unknown how to optimise treatment. The subset of elderly patients with a lower DLCO illustrates this as these patients have a more severe phenotype with poorer survival, advanced NYHA WHO functional class and reduced exercise capacity. Earlier and improved diagnosis in the elderly PAH population is vital so that these patients may receive early care. Older patients have been underrepresented in clinical trials for $\mathrm{PAH}$, but we hope future registries and trials will help to improve the understanding of this patient population and assess their treatment needs.

\section{Acknowledgements}

Medical writing support was provided by Lynda McEvoy (apothecom scopemedical ltd, Sevenoaks, UK), which was funded by Actelion Pharmaceuticals Ltd (Allschwil, Switzerland).

\section{References}

1 Galiè N, Torbicki A, Barst R, et al. Guidelines on diagnosis and treatment of pulmonary arterial hypertension. The Task Force on Diagnosis and Treatment of Pulmonary Arterial Hypertension of the European Society of Cardiology. Eur Heart J 2004; 25: 2243-2278.

2 Peacock AJ, Murphy NF, McMurray JJ, et al. An epidemiological study of pulmonary arterial hypertension. Eur Respir J 2007; 30: 104-109.

3 Frost AE, Badesch DB, Barst RJ, et al. The changing picture of patients with pulmonary arterial hypertension in the United States: how REVEAL differs from historic and non-US Contemporary Registries. Chest 2011; 139: 128-137.

4 Humbert M, Sitbon O, Chaouat A, et al. Pulmonary arterial hypertension in France. Results from a national registry. Am J Respir Crit Care Med 2006; 173: 1023-1030.

5 Escribano-Subias P, Blanco I, López-Meseguer M, et al. Survival in pulmonary hypertension in Spain: insights from the Spanish registry. Eur Respir J 2012; 40: 596-603.

6 Ling Y, Johnson MK, Kiely DG, et al. Changing demographics, epidemiology, and survival of incident pulmonary arterial hypertension: results from the pulmonary hypertension registry of the United Kingdom and Ireland. Am J Respir Crit Care Med 2012; 186: 790-796. 
Jansa P, Jarkovsky J, Al-Hiti H, et al. Epidemiology and long-term survival of pulmonary arterial hypertension in the Czech Republic: a retrospective analysis of a nationwide registry. BMC Pulm Med 2014; 14: 45.

8 Simonneau G, Gatzoulis MA, Adatia I, et al. Updated clinical classification of pulmonary hypertension. J Am Coll Cardiol 2013; 62: D34-D41.

9 Benza RL, Miller DP, Barst RJ, et al. An evaluation of long-term survival from time of diagnosis in pulmonary arterial hypertension from the REVEAL registry. Chest 2012; 142: 448-456.

10 Zhang R, Dai LZ, Xie WP, et al. Survival of Chinese patients with pulmonary arterial hypertension in the modern treatment era. Chest 2011; 140: 301-309.

11 Thenappan T, Shah SJ, Rich S, et al. Survival in pulmonary arterial hypertension: a reappraisal of the NIH risk stratification equation. Eur Respir J 2010; 35: 1079-1087.

12 Benza RL, Miller DP, Gomberg-Maitland M, et al. Predicting survival in pulmonary arterial hypertension: insights from the Registry to Evaluate Early and Long-Term Pulmonary Arterial Hypertension Disease Management (REVEAL). Circulation 2010; 122: 164-172.

13 Hoeper MM, Huscher D, Ghofrani HA, et al. Elderly patients diagnosed with idiopathic pulmonary arterial hypertension: results from the COMPERA registry. Int J Cardiol 2013; 168: 871-880.

14 Lee WT, Ling Y, Sheares KK, et al. Predicting survival in pulmonary arterial hypertension in the UK. Eur Respir J 2012; 40: 604-611.

15 Badesch DB, Raskob GE, Elliott CG, et al. Pulmonary arterial hypertension: baseline characteristics from the REVEAL Registry. Chest 2010; 137: 376-387.

16 Jing ZC, Xu XQ, Han ZY, et al. Registry and survival study in Chinese patients with idiopathic and familial pulmonary arterial hypertension. Chest 2007; 132: 373-379.

17 Rich S, Dantzker DR, Ayres SM, et al. Primary pulmonary hypertension. A national prospective study. Ann Intern Med 1987; 107: 216-223.

18 McGoon MD, Benza RL, Escribano-Subias P, et al. Pulmonary arterial hypertension: epidemiology and registries. J Am Coll Cardiol 2013; 62: D51-D59.

19 Humbert M, Sitbon O, Yaïci A, et al. Survival in incident and prevalent cohorts of patients with pulmonary arterial hypertension. Eur Respir J 2010; 36: 549-555.

20 D’Alonzo GE, Barst RJ, Ayres SM, et al. Survival in patients with primary pulmonary hypertension. Results from a national prospective registry. Ann Intern Med 1991; 115: 343-349.

21 Thenappan T, Ryan JJ, Archer SL. Evolving epidemiology of pulmonary arterial hypertension. Am J Respir Crit Care Med 2012; 186: 707-709.

22 Kane GC, Maradit-Kremers H, Slusser JP, et al. Integration of clinical and hemodynamic parameters in the prediction of long-term survival in patients with pulmonary arterial hypertension. Chest 2011; 139: 1285-1293.

23 Humbert M, Sitbon O, Chaouat A, et al. Survival in patients with idiopathic, familial, and anorexigen-induced pulmonary arterial hypertension in the modern management era. Circulation 2010; 122: 156-163.

24 Thenappan T, Shah SJ, Rich S, et al. A USA-based registry for pulmonary arterial hypertension: 1982-2006. Eur Respir J 2007; 30: 1103-1110.

25 Shapiro S, Traiger GL, Turner M, et al. Sex differences in the diagnosis, treatment, and outcome of patients with pulmonary arterial hypertension enrolled in the registry to evaluate early and long-term pulmonary arterial hypertension disease management. Chest 2012; 141: 363-373.

26 Jiang X, Humbert M, Jing ZC. Idiopathic pulmonary arterial hypertension and its prognosis in the modern management era in developed and developing countries. In: Humbert M, Souza R, Simonneau G, eds. Pulmonary Vascular Disorders. Basel, Karger, 2012; pp. 85-93

27 Health and Social Care Information Centre. National Audit of Pulmonary Hypertension 2013. www.hscic.gov.uk/ catalogue/PUB13318/nati-pulm-hype-audi-2013-rep.pdf Date last accessed: August 28, 2014.

28 NHS Information Centre. National Audit of Pulmonary Hypertension 2010. www.hscic.gov.uk/catalogue/ PUB02651/nati-pulm-hype-audi-2010-rep.pdf Date last accessed: August 28, 2014

29 NHS Information Centre. National Audit of Pulmonary Hypertension 2011. www.hscic.gov.uk/catalogue/ PUB04619/nati-pulm-hype-audi-2011-rep.pdf Date last accessed: August 28, 2014.

30 Health and Social Care Information Centre. National Audit of Pulmonary Hypertension 2012. www.hscic.gov.uk/ catalogue/PUB10535/nati-pulm-hype-audi-2012-rep.pdf Date last accessed: August 28, 2014

31 Pauwaa S, Machado RF, Desai AA. Survival in pulmonary arterial hypertension: a brief review of registry data. Pulm Circ 2011; 1: 430-431.

32 Galiè N, Hoeper MM, Humbert M, et al. Guidelines for the diagnosis and treatment of pulmonary hypertension: the Task Force for the Diagnosis and Treatment of Pulmonary Hypertension of the European Society of Cardiology (ESC) and the European Respiratory Society (ERS), endorsed by the International Society of Heart and Lung Transplantation (ISHLT). Eur Heart J 2009; 30: 2493-2537.

33 Desai AA, Machado RF. Diagnostic and therapeutic algorithm for pulmonary arterial hypertension. Pulm Circ 2011; 1: $122-124$

34 OECD. OECD Regions at a Glance 2013. Paris, OECD Publishing, 2013

35 Sitbon $\mathrm{O}$, Humbert $\mathrm{M}$, Nunes $\mathrm{H}$, et al. Long-term intravenous epoprostenol infusion in primary pulmonary hypertension: prognostic factors and survival. J Am Coll Cardiol 2002; 40: 780-788.

36 Miyamoto S, Nagaya N, Satoh T, et al. Clinical correlates and prognostic significance of six-minute walk test in patients with primary pulmonary hypertension. Am J Respir Crit Care Med 2000; 161: 487-492.

37 Montani D, Kemp K, Dorfmuller P, et al. Idiopathic pulmonary arterial hypertension and pulmonary venoocclusive disease: similarities and differences. Semin Respir Crit Care Med 2009; 30: 411-420.

38 Cai M, Zhu M, Ban C, et al. Clinical features and outcomes of 210 patients with idiopathic pulmonary fibrosis. Chin Med J (Engl) 2014; 127: 1868-1873.

39 Mejía M, Carrillo G, Bojas-Serrano J, et al. Idiopathic pulmonary fibrosis and emphysema: decreased survival associated with severe pulmonary arterial hypertension. Chest 2009; 136: 10-15.

40 Jing ZC, Xu XQ, Badesch DB, et al. Pulmonary function testing in patients with pulmonary arterial hypertension. Respir Med 2009; 103: 1136-1142.

41 Trip P, Nossent EJ, de Man FS, et al. Severely reduced diffusion capacity in idiopathic pulmonary arterial hypertension: patient characteristics and treatment responses. Eur Respir J 2013; 42: 1575-1585. 
42 Souza R, Fernandes CJ, Hoeper MM. Carbon monoxide diffusing capacity and the complexity of diagnosis in pulmonary arterial hypertension. Eur Respir J 2014; 43: 963-965.

43 Ruiz-Cano MJ, Escribano P, Alonso R, et al. Comparison of baseline characteristics and survival between patients with idiopathic and connective tissue disease-related pulmonary arterial hypertension. J Heart Lung Transplant 2009; 28: 621-627.

44 Chandra S, Shah SJ, Thenappan T, et al. Carbon monoxide diffusing capacity and mortality in pulmonary arterial hypertension. J Heart Lung Transplant 2010; 29: 181-187.

45 Chung L, Domisc RT, Lingala B, et al. Survival and predictors of mortality in systemic sclerosis-associated pulmonary arterial hypertension: outcomes from the pulmonary hypertension assessment and recognition of outcomes in scleroderma registry. Arthritis Care Res (Hoboken) 2014; 66: 489-495. 